\title{
Retinitis pigmentosa, ataxia, and mental retardation associated with mitochondrial DNA mutation in an Italian family
}

Piero Puddu, Piero Barboni, Vilma Mantovani, Pasquale Montagna, Angelina Cerullo, Michela Bragliani, Carla Molinotti, Roberto Caramazza

\begin{abstract}
An Italian pedigree including two sisters and their mother affected by a neuro-ophthalmic disease characterised by retinitis pigmentosa, ataxia, and psychomotor retardation is reported. Molecular analysis of mitochondrial DNA showed the presence of heteroplasmic 8993 point mutation in the subunit 6 of the ATPase gene. The clinical features and genetic findings in this family were comparable with those recently described in an English family. The mitochondrial DNA analysis of the family showed a correlation between the amount of mutated DNA and the disease severity in the probands, and indicated the presence of a threshold amount of mutated genome inducing ophthalmic defects. Moreover, the comparative analysis of blood, hairs, muscle, and urinary tract epithelia of two probands revealed an essentially similar distribution of mutated and wild type mitochondrial genomes. Our results suggest that the 8993 mitochondrial DNA mutation characterises a disease with similar clinical features in different populations.
\end{abstract}

(Brf Ophthalmol 1993; 77: 84-88)

A variety of ophthalmic findings such as retinitis pigmentosa, progressive external ophthalmoplegia, and optic atrophy may occur in different associations with neurological diseases characterised by disorders of mitochondrial functions. $^{1-4}$ Mitochondria are cytoplasmic organelles essential to cellular bioenergy, producing ATP by means of oxidative phosphorylation. Each mitochondrion contains several copies of a circular double stranded molecule of DNA (mtDNA) of 16569 nucleotide pairs (np) coding for two rRNAs, 22 tRNAs, and 13 of the 61 protein subunits of mitochondrial respiratory complexes: NADH dehydrogenase subunits (complex I), cytochrome b subunit (complex III), cytochrome c oxidase subunits (complex IV), and ATP synthase subunits (complex V). ${ }^{5-7}$ The mtDNA is transmitted through the maternal lineage and the mitochondria of the zygote are provided only by the ovum. ${ }^{8}$

Genetic studies of some neuro-ophthalmic diseases have revealed various defects in mtDNA. Point mutations of mtDNA were reported as the genetic defect in Leber's hereditary optic neuropathies, ${ }^{9-12}$ myoclonus epilepsy with ragged red fibres (MERRF), ${ }^{13}$ mitochondrial myopathy, encephalopathy, lactic acidosis and stroke-like episodes syndrome (MELAS), ${ }^{1+}$ and in other mitrochondrial myo- pathy, ${ }^{15-18}$ Other genetic defects of mtDNA as single or multiple deletions and tandem duplications were described in chronic progressive external ophthalmoplegia, Kearns-Sayre syndrome, and encephalomyopathies. ${ }^{19-24}$ A variable proportion of mutated and wild type $\mathrm{mt}$ genomes may be present in different cells and tissues; this condition goes by the name of heteroplasmy and is a typical feature of mitochondrial diseases. ${ }^{10-25}$ The variable degrees of heteroplasmy in tissues with different energy requirements may explain the widely different clinical features often encountered in mitochondrial diseases.

Holt $e t a l^{26}$ recently reported a point mutation of np 8993 of mtDNA in a family with a new neuro-ophthalmic disease characterised by retinitis pigmentosa, dementia, seizures, ataxia, proximal neurogenic muscle weakness, sensory neuropathy, and maternal inheritance.

We report an identical association between clinical and genetical features in an Italian family. We found the presence of the same heteroplasmic mutation in three maternally related family members; moreover we evaluated the segregation of mutated and wild type mtDNA in different tissues.

\section{Patients and methods}

PATIENTS

The pedigree of this Italian family included three affected female (two sisters and their mother) and other three asymptomatic relatives (Fig 1A). The family history had no records of other relatives with neuro-ophthalmic disorders.

Patient II-1, a 41-year-old woman, was the mother of two daughters. She complained of lifelong muscle fatigue, headache, and, in the last years, some memory loss and mild paraesthesia localised in her toes. Examination showed diffuse hypotonia, slight proximal leg weakness, loss of knee and ankle jerks, and minimal Romberg sign. Ophthalmoscopic examination was normal; electroretinography showed normality of photopic cone and scotopic rod responses (Fig $2)$. Creatinine kinase (CK), lactate at rest and after a standardised effort, electrocardiogram (ECG), electroencephalogram (EEG), brain computed tomography (CT), quantitative electromyelogram (EMG), and motor and sensory conduction velocities (CV) were all normal. Muscle biopsy was normal, in particular ragged-red fibres were absent. Spectrophotometric assay of respiratory chain enzymes was also normal. 
Figure 1 (A) The pedigree of the family: filled symbols indicate affected individuals. $(B)$ The gel electrophoresis shows the Ava I digestion of amplified mtDNA with primers EM1/MT19. Fragment 872 indicates the wild type mtDNA and fragments 656 and 216 indicate the mutated mtDNA. (C) shows the subsequent Southern blotting and hybridisation with $M T 17$ probe. $M=$ size marker; $b p=$ base pair.

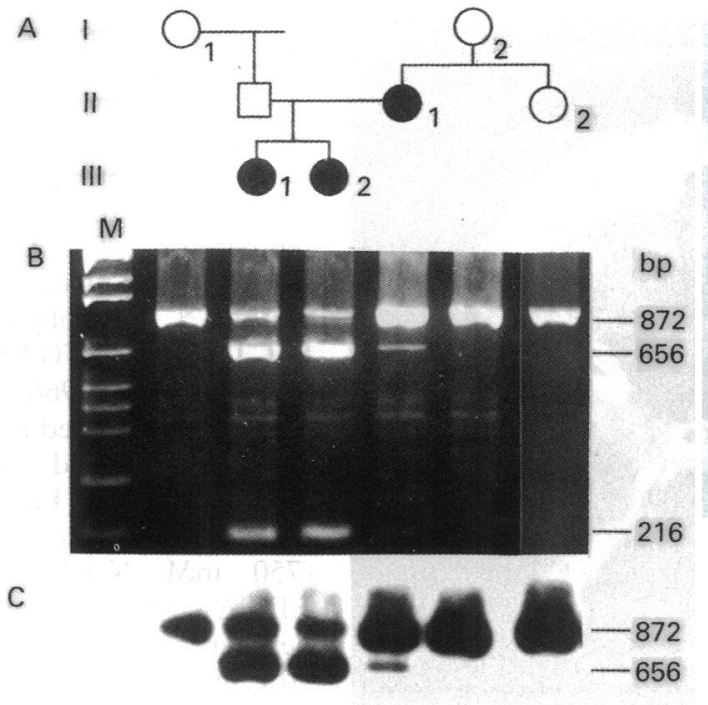

Patient III-1, her 13-year-old daughter, had had neonatal jaundice and psychomotor retardation since birth. During infancy she had several episodes of marked worsening of muscle strength, ataxia, vomiting, and confusion upon trivial fevers. On examination, dysarthria, diffuse hypotonia, and muscle wasting with weakness, dysmetria, incoordination, gait ataxia with a Romberg sign, and weak tendon jerks were found. Ophthalmoscopic examination showed a bilateral pigmentary pattern of retinitis pigmentosa, with pigmentary bone spicule-like deposition in the midperiphery (Fig 3). Electroretinography disclosed subnormal photopic responses: amplitudes of photopic a and b-waves were reduced and b-wave implicit time was prolonged (Fig 2). CK lactate at rest and after effort, ECG were normal. Brain CT showed cerebellar and brainstem atrophy (Fig 4); EEG slow background activity and paroxysmal (spikes, spike slow waves) diffuse activity; EMG showed neurogenic atrophy and decreased amplitude of sensory evoked potentials (SEP) in the legs. Muscle biopsy was normal without ragged-red fibres. Respiratory chain enzymes were normal on spectrophotometric assay. Patient III-2, 19-year-old daughter, had neonatal icterus and febrile convulsions at 6 months of age. Severe psychomotor retardation and hypotonia were present since birth. Marked worsening of strength, gait, and confusion

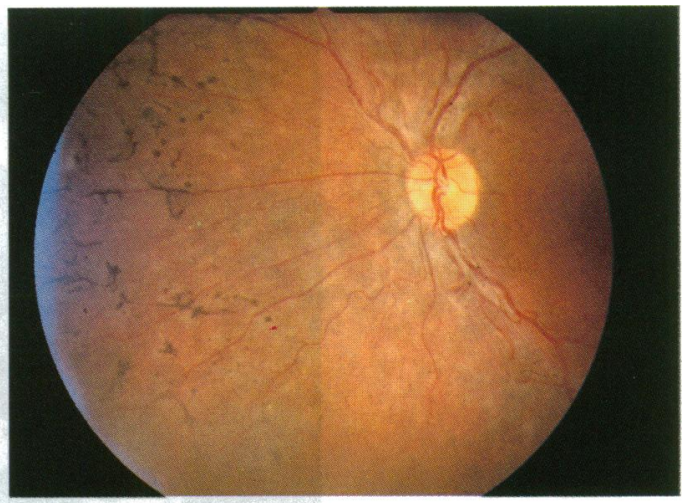

Figure 3 Fundus photograph from right eye of patient III-I demonstrating vessel tortuosity, wrinkling of inner limiting membrane and bone spicule pigment forms in all quadrants of the midperiphery.

occurred upon even trivial fevers. Visual loss became apparent since the age of 16 years. She presented fundus changes in both eyes, typical of advanced retinitis pigmentosa (pigmentary bone spicule-like depositions, arteriolar narrowing, pallor of the disc); an ERG recording showed a reduction in photopic a and b-wave amplitudes with a prolonged implicit time (Fig 2). Neurological signs comprised besides the severe mental retardation, dysarthria, muscle hypotonia without any muscle weakness or atrophy, dystonic posturing of trunk and limbs, and gait ataxia. CK, ECG, EEG, and resting lactate were normal. Brain CT showed cerebellar brainstem, and slight cerebral cortical atrophy; EMG showed neurogenic atrophy and decreased amplitude of sensory potentials.

Ophthalmoscopic examination performed also in subjects I-1, I-2 and II-2, who were completely asymptomatic, was normal; electroretinographic testing of grandmother (I-2) showed normal photopic cone and scotopic rod responses.

\section{Methods}

Molecular analysis of mtDNA was performed in the six family members (Fig 1). Since the 8993 mtDNA mutation creates an Ava $\mathrm{I}^{26}$ and removes a Bst NI restriction site, we performed an endonuclease digestion with these enzymes, after polymerase chain reaction (PCR) amplification of mtDNA. ${ }^{27}$ Total DNA was extracted from leucocytes, epithelial cells of the urinary tract
Figure 2

Electroretinographic findings of patients $I I-I$, III-1, and II-2. In the two sisters cone $a$ and $b$-wave amplitudes were reduced and $b$-wave implicit time was prolonged. In the mother photopic cone and scotopic rod responses were normal. $R E=$ right eye; $L E=$ left eye; $S E=$ skin electrodes; $G A=$ general anaesthesia.
Patient III-1

Patient III-2

Patient II-1

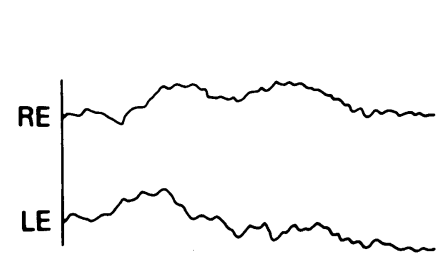

SE

$$
\begin{aligned}
& 10 \mu \mathrm{VJ} \\
& 15.33 \mathrm{~ms}
\end{aligned}
$$

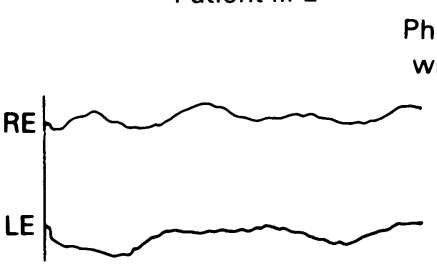

GA

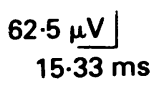

Photopic

white

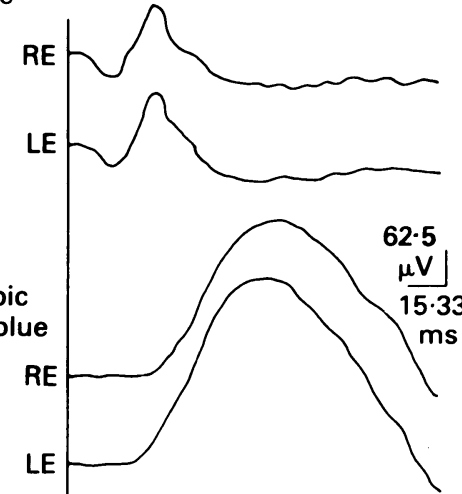


Figure 4 Brain computed tomography of patient III-1 showing marked cerebellar and brainstem atrophy.

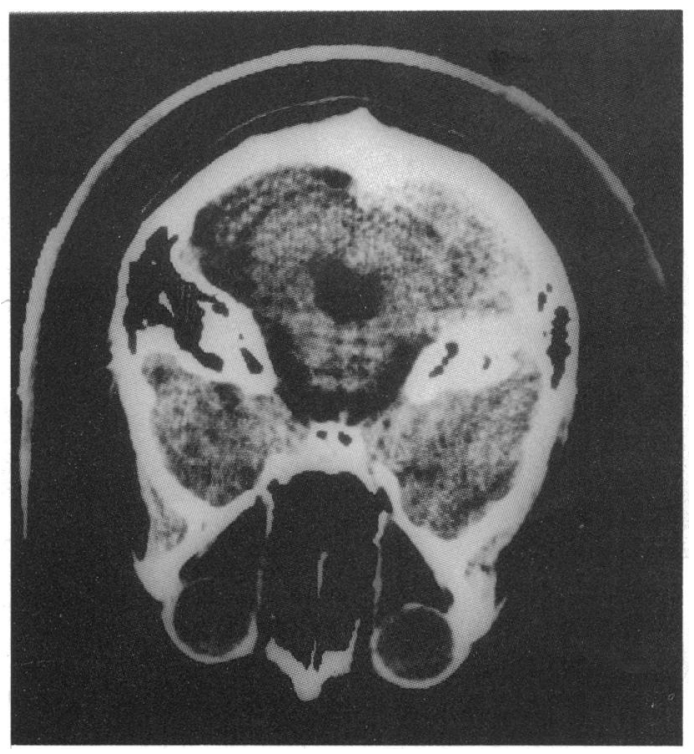

and from fractionated homogenates of frozen muscle with phenol and chloroformisoamylalcohol, precipitated with ethanol and solubilised in $10 \mathrm{mM}$ Tris-HC1/1 mM EDTA $\mathrm{pH} 8 .^{28}$ DNA preparation from hairs was performed by adding $0.15 \mathrm{mg}$ proteinase $\mathrm{K}, 50 \mu \mathrm{l}$ sodium dodecyl sulphate (SDS) $20 \%, 0.05 \mathrm{mg}$ RNAse, $40 \mu \mathrm{m}$ dithiothreitol for 70 hours, before the conventional DNA extraction. The pairs of oligonucleotide primers EM1 (5'-ATTAAGAGAACCAACACCTC-3' from 8335 to $8354 \mathrm{np} / \mathrm{MT} 19$ (5'TATGTGTTGTCGTGCAGGTAGA-3' from 9206 to $9185 \mathrm{np}$ ), and MT39 (5'-TCCTGCCTCACTCATTTACA-3' from 8786 TO $8805 \mathrm{np}$ )/MT19 were used to amplify 872 and $421 \mathrm{np}$ regions of mtDNA respectively, including the Ava I and Bst NI sites. ${ }^{5}$ Twenty five cycles of PCR amplification were completed with $1 \mu \mathrm{g}$ of DNA in a $100 \mu \mathrm{l}$ volume reaction containing $50 \mathrm{mM} \mathrm{KCl}, 10 \mathrm{mM}$ Tris- $\mathrm{HCl}(\mathrm{pH} \mathrm{8.3)}, 1.5 \mathrm{mM} \mathrm{MgCl}, 100 \mu \mathrm{g} / \mathrm{ml}$ gelatin, $200 \mu \mathrm{M}$ each of dATP, dCTP, dGTP, and dTTP, $1 \mu \mathrm{M}$ of each primer and 2.5 units Taq-polymerase (Perkin Elmer-Cetus, Norwalk, USA). Each cycle consisted of $94^{\circ} \mathrm{C}$ denaturation for 90 seconds, $55^{\circ} \mathrm{C}$ annealing for 150 seconds and $72^{\circ} \mathrm{C}$ extension for 4 minutes. ${ }^{29}$ The presence of the $8993 \mathrm{mtDNA}$ mutation was detected by overnight digestion of the total amplified DNA (about $2 \mu \mathrm{g}$ ) with 10 units of Ava I and Bst NI restriction enzymes (New England Biolabs, Beverly, MA, USA). The samples were then electrophoresed on $3 \%$ Nusieve plus $1 \%$ agarose gel stained with $1 \mu \mathrm{g} / \mathrm{ml}$ ethidium bromide and photographed under ultraviolet light.

After staining, the gel was denatured in $0.4 \mathrm{~N}$ $\mathrm{NaOH} / 0.6 \mathrm{M} \mathrm{NaCl}$ for 30 minutes at room temperature and neutralised in $1.5 \mathrm{M} \mathrm{NaCl} / 0.5$ $\mathrm{M}$ Tris- $\mathrm{HCl} \mathrm{pH} 7.5$ for 30 minutes at room temperature. The DNA was then transferred overnight to a nylon membrane by the Southern method. ${ }^{30}$ The oligonucleotide probe MT17 5' CTATTGGTTGAATGAGTAGGCTGA - 3 from 8989 to $8966 \mathrm{np}$ ), 5'end-labelled with ${ }^{32} \mathrm{P}$-dATP, was used for hybridisation. The filter was prehybridised for 1 hour at $37^{\circ} \mathrm{C}$ in $5 \times$ Denhardt's $(0 \cdot 1$ Ficoll/ $0 \cdot 1 \%$ polyvinylpyrrolidone $/ 0 \cdot 1 \%$ bovine serum albumin), $5 \times \mathrm{SSPE}$ $\left(\begin{array}{lllll}750 & \mathrm{mM} & \mathrm{NaCl} / 50 & \mathrm{mM} & \mathrm{NaH}_{2} \mathrm{PO}_{4} / 5 \quad \mathrm{mM}\end{array}\right.$ EDTA), $0.5 \%$ SDS and $200 \mathrm{mg} / \mathrm{ml}$ of denatured herring sperm, and then hybridised for 1 hour at $50^{\circ} \mathrm{C}$ in a solution consisting of the prehybridisation solution plus the radiolabelled probe $\left(2 \times 10^{6} \mathrm{cpm} / \mathrm{ml}\right)$. After hybridisation the filter was washed in $0 \cdot 1 \times \mathrm{SSPE} / 0 \cdot 1 \%$ SDS for 10 minutes at room temperature and for 10 minutes at $40^{\circ} \mathrm{C}$. The filter was then exposed to Kodak XAR-5 at $-80^{\circ} \mathrm{C}$ with intensifying screen for 2 hours and/or overnight. In order to test the absence of $8993 \mathrm{mtDNA}$ mutation in the Italian population, we included 51 unrelated healthy controls in the study.

\section{Results}

The Ava I and Bst NI restriction analyses were performed in mtDNA from leucocytes of the whole pedigree. Both daughters and their mother presented the Ava I restriction site, producing the 656 and $216 \mathrm{np}$ fragments, because of the 8993 mutation (Fig 1B). Likewise, all three probands lacked the Bst NI site owing to the same mutation (Fig 5A).

In restriction analyses with both Ava I and Bst NI enzymes, the presence of heteroplasmy in leucocytes was revealed by the presence of all three fragments. A residual amount of wild type mtDNA was found in variable proportions in the three probands: about $25 \%$ in both sisters and about $90 \%$ in their mothers. These results were confirmed by the Southern blotting and hybridisation of the digestion (Fig 1C).

Additional molecular analysis was performed in mtDNA obtained from epithelial cells of the urinary tract of subjects I-2, II-1, and III-1, from muscle of patients II-1 and III-1, and from hairs of patient III-1 (Fig 5B). The degree of heteroplasmy in all three probands detected in muscle, Bst NI digestion of amplified mtDNA with primers MT39/MT19.

Fragment 421 indicates the mutated mtDNA and fragments 214 and 207 indicate the wild type mtDNA. $M=$ size marker $b p=$ base pair. (B) Analysis of muscle, hair, and urinary tract epithelia mtDNA. The panel shows the Ava I digestion of amplified miDNA with primers MT $39 / M T 19$. Fragment 421 indicates the wildtype mtDNA and fragments 216 and 205 indicate the mutated mtDNA. $M=$ size marker; $m=$ muscle $; b=$ blood; $h=$ hair; $u=$ urinary tract epithelia.

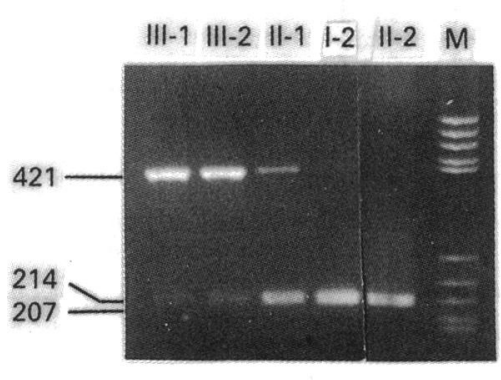

A

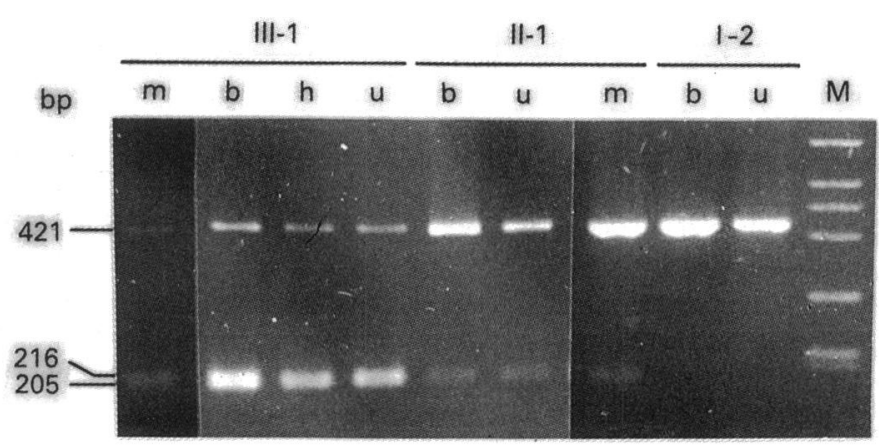

B 
urinary tract epithelia and hair was the same as that found in blood.

The Ava I and Bst NI restriction analyses were also performed in both grandmothers (I-1 and I2) and in the aunt of the sisters (II-2). The three subjects did not show the mutation either in blood (I-1, I-2 and II-2) or in urinary cells (I-2). All the 51 unrelated healthy controls studied did not present the mutation.

\section{Discussion}

Retinitis pigmentosa, ataxia, and mental retardation were the clinical features present both in our Italian family and in the pedigree previously described by Holt et al. ${ }^{26}$ Therefore, these clinical signs seem to be typical of this new neuro-ophthalmic disease. However, the same findings were found by Tatuch et al in a family which presented, in addition, the clinical phenotype of Leigh syndrome. ${ }^{31}$

Molecular analysis showed the presence of the 8993 point mutation of mtDNA in all probands of this family. This mutation causes a transversion from thymine to guanine, converting a highly conserved leucine into arginine in ATPase subunit 6 . A variable proportion of mutated and wildtype mtDNA (heteroplasmy) was present in the probands and the percentage of wildtype decreased in the second affected generation. These findings are in line with the hypothesis that mutated mitochondria shift toward a homoplasmic condition during the meiotic segregation, possibly due to a positive selection of defective mitochondria. ${ }^{32-35}$

As in the other two pedigrees, we found a correlation between the amount of mutated mtDNA and the disease severity in the probands; the two sisters showed higher levels of mutated mtDNA (about 75\%) than their mother (about $10 \%$ ) (Fig 1). In our family the mtDNA analysis seems to indicate the presence of a threshold amount of mutated mtDNA inducing the retinal degeneration. More than one type of pigmentary retinopathy of different severity can be associated with mitochondrial diseases. ${ }^{136}$ The finding of defective mitochondria in the retinal pigment epithelium suggests a correlation between degenerative processes of the retina and defects in oxidative phosphorylation. ${ }^{37}$

Moreover, we evaluated the mitotic segregation of the two mtDNA types in different tissues. The comparative analysis of blood, muscle, hairs, and urinary tract epithelia of two probands revealed an essentially similar heteroplasmy (Fig 5B). However, we are unable to rule out the hypothesis of a higher number of mutated $\mathrm{mt}$ genomes in brain and retina.

We did not find traces of mutation in the grandmothers and in the aunt of the sisters, though we used a more sensitive radioisotopic method (Fig 1). Furthermore, the analysis of urinary tract epithelia of the grandmother (I-2) excluded a different segregation of mtDNA in this tissue. This result suggested a recent origin of the mutation in the family. Our genetic findings confirmed the mitochondrial origin of the disease.

Oúr results indicate that the $8993 \mathrm{mtDNA}$ mutation characterises a new neuro-ophthalmic disease, with typical clinical and genetic features, which remains unchanged even in different populations.

We are particularly indebted to the family members, without whose interest and cooperation no work would have been possible. The genetical assistance of A Zacchini, P Malpassi, P Selva, D Bastia, and the electrophysiological assistance of P Fiorini, L Fulco, and S Bontempi are gratefully acknowledged. We wish to thank F Barboni for his valued contribution and assistance in this work.

1 Mullie MA, Harding AE, Petty RKH, Ikeda H, MorganHughes JA, Sanders MD. The retinal manifestations of mitochondrial myopathy. Arch Ophthalmol 1958; 103: 182530.

2 Drachman DA. Ophthalmoplegia plus. The neurodegenerative disorders associated with progressive external ophthaldisorders associated with progressive
moplegia. Arch Neurol 1968; 18: 654-74.

3 Di Mauro S, Bonilla E, Zeviani M, Nakagawa M, De Vivo DC. Mitochondrial myopathies. Ann Neurol 1985; 17: 521-38.

4 Nikoskelainen EK, Savontaus ML, Wanne OL, Katila MJ, Nummelin KU. Leber's hereditary optic neuroretinopathy, a maternally inherited disease. Arch Ophthalmol 1987; 105 : 665-71.

5 Anderson S, Bankier AT, Barrel BG, de Bruijn MHL, Coulson AR, Drouin J, et al. Sequence and organization of the human mitochondrial genome. Nature 1981; 290: 457-65.

6 Chomyn A, Mariottini P, Cleeter MWJ, Ragan CI, Doolittle RF, Matsuno-Yagi A, et al. Six unidentified reading frames of human mitochondrial DNA encode components of the respiratory-chain NADH dehydrogenase subunit. Nature respiratory-chain

7 Chomyn A, Cleeter MWJ, Ragan CI, Riley M, Doolittle RF Attardi G. URF6, last unidentified reading frame of human mt DNA, codes for an NADH dehydrogenase subunit. Science 1986; 234: 614-8.

8 Giles RE, Blanc H, Cann HM, Wallace DC. Maternal inheritance of human mitochondrial DNA. Proc Natl Acad Sci USA 1980; 77: 6715-19.

9 Wallace DC, Singh G, Lott MT, Hodge JA, Schurr TG, Lezza AMS, et al. Mitochondrial DNA mutation associated with Leber's hereditary optic neuropathy. Science 1988; 242 1427-30.

10 Huoponen K, Vilkki J, Aula P, Nikoskelainen EK, Savontaus ML. A new mt DNA mutation associated with Leber ML. A new mt DNA mutation associated with Leber
hereditary optic neuroretinopathy. Am f Hum Genet 1991; 48: 1147-53.

11 Howell N, Bindoff LA, McCullough DA, Kubacka I, Poulton J, Mackey $\mathrm{D}$, et al. Leber hereditary optic neuropathy: identification of the same mitochondrial NDI mutation in six pedigrees. Am F Hum Genet 1991; 49: 939-50.

12 Johns DR, Berman J. Alternative, simultaneous complex 1 mitochondrial DNA mutation in Leber's hereditary optic neuropathy. Biochem Biophys Res Commum 1991; 174: 1324 30 .

13 Shoffner JM, Lott MT, Lezza AMS, Seibel P, Ballinger SW, Wallace DC. Myoclonic epilepsy and ragged-red fiber disease (MERRF) is associated with a mitochondrial DNA tRNALys mutation. Cell 1990; 61: 931-7.

14 Tanaka M, Ino $\mathrm{H}$, Ohno K, Ohbayashi T, Ikebe S, Sano T, et al. Mitochondrial DNA mutation in mitochondrial myopathy, encephalopathy, lactic acidosis, and stroke-like myopathy, encephalopathy, lactic acidosis, and stroke-like
episodes (MELAS). Biochem Biophys Res Commun 1991; episodes (M

15 Tanaka M, Ino H, Ohno K, Hattori K, Sato W, Ozawa T, et al. Mitochondrial mutation in fatal infantile cardiomyopathy. Lancet 1990; 336: 1452 .

16 Zeviani M, Gellera C, Antozzi C, Rimoldi M, Morandi L, Villani F, et al. Maternally inherited myopathy and cardiomyopathy: association with mutation in mitochondrial DNA tRNA ${ }^{\text {LEu(UUR }}$. L Lancet 1991; 338: 143-7.

17 Yoon KL, Aprille JR, Ernst SG. Mitochondrial tRNA ${ }^{\text {th }}$ mutation in fatal infantile respiratory enzyme deficiency. Biochem Biophys Res Commun 1991; 176: 1112-5.

18 Ozawa T, Tanaka M, Sugiyama S, Ino H, Ohno K, Hattori K, et al. Patients with idiopathic cardiomyopathy belong to the same mitochondrial DNA gene family of Parkinson's disease and mitochondrial encephalomyopathy. Biochem Biophys and mitochondrial encephalomy

19 Holt IJ, Harding AE, Morgan-Hughes JA. Deletion of muscle mitochondrial DNA in patients with mitochondrial myopathies. Nature 1988; 331: 717-9.

20 Lestienne P, Ponsot G, Kearns-Sayre syndrome with muscle mitochondrial DNA deletion. Lancet 1988; i: 885

21 Moraes CT, Di Mauro S, Zeviani M, Lombes A, Shanske S Miranda AS, et al. Mitochondrial DNA deletions in progressive external ophthalmoplegia and Kearns-Sayre syndrome. N Engl F Med 1989; 320: 1293-9.

22 Saifuddin Noer A, Marzuki S, Trounce I, Byrne E. Mitochondrial DNA deletions in encephalomyopathy. Lancet 1988; ii: $1253-4$.

23 Zeviani M, Servidei S, Gellera C, Bertini E, Di Mauro S, Di Donato S. An autosomal dominant disorder with multiple deletions of mitochondrial DNA starting at the D-loop deletions of mitochondrial DNA starting at the D-loop region. Nature 1989; 339: 309-11.

24 Poulton J, Deadman ME, Gardiner RM. Duplication of mitochondrial DNA in mitochondrial myopathy. Lance 1989; i: 236-9. 
25 Holt IJ, Miller DH, Harding AE. Genetic heterogeneity and mitochondrial DNA heteroplasmy in Leber's hereditary optic neuropathy. F Med Genet 1989; 26: 739-43.

26 Holt IJ, Harding AE, Petty RKH, Morgan-Hughes JA. A new mitochondrial disease associated with mitochondrial DNA heteroplasmy. Am $\mathcal{F}$ Hum Genet 1990; 46: 428-33.

27 Saiki RK, Gelfand DH, Stoffel S, Sharf SJ, Higuchi R, Horn GT, et al. Primer-directed enzymatic amplification of DNA with a thermostable DNA polymerase. Science 1988; 239: 487-91.

28 Maniatis T, Fritsch EF, Sambrook J. Molecular cloning: a laboratory manual. New York: Cold Spring Harbor Laboratory, 1982.

29 Cortelli P, Montagna P, Avoni P, Sangiorgi S, Bresolin N, Moggio M, et al. Leber's hereditary optic neuropathy. Genetic, biochemical, and phosphorus magnetic resonance spectroscopy study in an Italian family. Neurology 1991; 41: 1211-5.

30 Southern EM. Detection of specific sequences among DNA fragments separated by gel electrophoresis. F Mol Biol 1975; 98: 503-17.

31 Tatuch Y, Christodoulou J, Feigenbaum A, Clarke JTR, Wherret J, Smith C, et al. Heteroplasmic mt DNA mutation
( $\mathrm{T}-\mathrm{g})$ at 8993 can cause Leigh disease when the percentage of abnormal mt DNA is high. Am $\mathcal{F}$ Hum Genet 1992; 50: 852-8.

32 Clarke A. Mitochondrial genome: defects, disease, and evolution. $\mathcal{F}$ Med Genet 1990; 27: 451-6.

33 Lott MT, Voljavec AS, Wallace DC. Variable genotype of Leber's hereditary optic neuropathy patients. Am f Ophthalmol 1990; 109: 625-31.

34 Bolhuis PA, Bleeker-Wagemakers EM, Ponne NJ, Van Schooneveld MJ, Westerveld A, Van der Bogert C, et al. Rapid shift in genotype of human mitochondrial DNA in a family with Leber's hereditary optic neuropathy. Biochem Biophys Res Commun 1990; 170: 994-7.

35 Barboni P, Mantovani V, Montagna P, Bragliani M, Cortelli P, Lugaresi E, et al. Mitochondrial DNA analysis in Leber's hereditary optic neuropathy. Ophthalmic Paediatr Genet 1992; in press.

36 Bosche J, Hammerstein W, Neuen-Jacob E, Schober R. Variation in retinal changes and muscle pathology in mitochondriopathies. Graefes Arch Clin Exp Ophthalmol

37 McKechnie NM, King M, Lee WR. Retinal pathology in the Kearns-Sayre syndrome. BrF Ophthalmol 1985; 69: 63-75. 